TITLE:

\title{
Agarotetrol: a source compound for low molecular weight aromatic compounds from agarwood heating
}

\author{
AUTHOR(S): \\ Takamatsu, Sakura; Ito, Michiho
}

\section{CITATION:}

Takamatsu, Sakura ... [et al]. Agarotetrol: a source compound for low molecular weight aromatic compounds from agarwood heating. Journal of Natural Medicines 2018, 72 (2): 537-541

\section{ISSUE DATE:}

2018-03

URL:

http://hdl.handle.net/2433/244285

\section{RIGHT:}

This is a post-peer-review, pre-copyedit version of an article published in Journal of Natural Medicines. The final authenticated version is available online at: http://dx.doi.org/10.1007/s11418-018-1185-y.; この論文は出版社版であり ません。引用の際には出版社版をご確認ご利用ください。; This is not the published version. Please cite only the published version. 


\title{
Agarotetrol: a source compound for low molecular weight aromatic compounds from agarwood heating
}

\author{
Sakura Takamatsu ${ }^{1} \cdot$ Michiho Ito $^{1}$ \\ ${ }^{1}$ Graduate School of Pharmaceutical Sciences, Kyoto University, \\ 46-29 Yoshidashimoadachi-cho, Sakyo-ku, Kyoto 606-8501, Japan \\ Tel: +81-75-753-4506 \\ e-mail: michihoi@pharm.kyoto-u.ac.jp
}

\begin{abstract}
Agarwood is known to generate a distinct fragrance on heating and is used as both a medicine and a fragrant wood. Low molecular weight aromatic compounds (LACs) such as benzylacetone are emitted from agarwood on heating and have a sedative effect on mice. These are detected exclusively in the headspace vapor of heated agarwood and are absent in the wood itself; hence, some compounds in agarwood are thought to be converted to LACs by the process of heating. In this study, different fractions obtained from agarwood were analyzed to reveal the source compounds of LACs. Some LACs detected in the resinous agarwood were absent from the non-resinous parts and confirmed as characteristic of the resinous parts. The essential oil and hydrosol of agarwood obtained by distillation were analyzed on GC-MS. Sesquiterpenes were detected in the essential oil, and sesquiterpenes and a variety of LACs were detected in the hydrosol. A hot water extract of agarwood remaining in the distillation flask after distillation was analyzed by HPLC, and agarotetrol was found to be the main compound. Purified agarotetrol was heated in a glass vial and its headspace vapor was analyzed by solid-phase microextraction-GC-MS. Benzylacetone and other LACs were detected. These results indicate that agarotetrol, a chromone derivative, contributes to the fragrance of agarwood through the generation of LACs on heating.
\end{abstract}

Key words agarwood $\cdot$ chromone derivatives $\cdot$ benzylacetone $\cdot$ hydrosol $\cdot$ essential oil $\cdot$ volatile compounds

\section{Introduction}

Agarwood is a resinous wood found in the trunks of Aquilaria and Gyrinops species [1]. It is used as a sedative in China, Korea, and Japan, and as an incense worldwide. Agarwood is formed in decaying or wounded trees. Phytochemical analyses of commercial agarwood pieces and agarwood oils have revealed that chromone derivatives, sesquiterpenes, and low molecular weight aromatic compounds (LACs) are the main constituents [2, 3, 4]. Chromone derivatives are non-volatile and non-fragrant compounds, while sesquiterpenes are volatile and fragrant. Chromone derivatives and sesquiterpenes are extracted by the organic solvents $\mathrm{MeOH}$, hexane, and ethyl acetate. LACs such as benzylacetone and benzaldehyde are volatile and fragrant compounds and are detected exclusively in the headspace vapor of heated agarwood $[4,5]$. Therefore, LACs are believed to contribute to the complex and distinct fragrance of agarwood on heating. In addition, inhalation of the vapor of some LACs has a sedative effect on mice, and benzylacetone in particular reduces mouse locomotor activity $[2,6]$. This may partly explain the pharmaceutical use of agarwood. The amounts of LACs in agarwood essential oil increase when distillation is performed after soaking pieces of the wood in water for several days [3]. It is therefore inferred that certain compounds in agarwood are extracted with water and generate LACs when heated. Some studies have suggested that chromone derivatives change to LACs. However, this has not yet been demonstrated [4, 7, 8]. In this study, different fractions obtained from agarwood, especially water-soluble compounds, were analyzed to reveal the source compounds of LACs.

\section{Materials and methods}

\section{Samples}


Agarwood samples were offered by Shoeido incense Co., (Kyoto, Japan). Non-resinous samples of agarwood were collected from the Experimental Station for Medical Plants at the Graduate School of Pharmaceutical Science, Kyoto University, and cut into small pieces to dry. Essential oil and hydrosol samples for GC-MS analysis were prepared by hydro-distillation of agarwood pieces using a glass distillation apparatus (Herb oil maker laboratory type, Tokyo Seisakusho Co. Ltd., Japan), and the distilled oil and hydrosol fractions were collected. The oil fraction was dissolved in diethyl ether, and dehydrated with anhydrous sodium sulfate. Likewise, the hydrosol fraction was extracted with diethyl ether, and the diethyl ether fraction was dehydrated by anhydrous sodium sulfate. A hot water extract of agarwood was freeze-dried, dissolved in $\mathrm{MeOH}$, filtered through filter paper (Tokyo Roshi Kaisha, Ltd., Japan) and evaporated. The resulting fraction was again dissolved in $\mathrm{MeOH}\left(1 \mathrm{mg} \mathrm{mL}^{-1}\right)$ and filtered (GL Chromatodisk 13P, $0.45 \mu \mathrm{m}$, GL Sciences, Tokyo, Japan) for HPLC analysis.

\section{Collection of volatile compounds}

The headspace (HS)-solid-phase microextraction (SPME) method was used in this experiment to collect the volatile compounds. Samples were put in glass vials (Supelco Inc., Bellefonte, PA), sealed with caps with holes and polytetrafluoroethylene-faced silicone septa (Supelco Inc.) and the vial containing sample was heated on a hot plate for $10 \mathrm{~min}$ at $190-200{ }^{\circ} \mathrm{C}$. The surface of hot plate was measured with digital thermometer (CT-01, Custom corporation) fitted with thermocouple prove (TS05, Custom corporation). After heating, an SPME fiber (polydimethylsiloxane $100 \mu \mathrm{m}$, Supelco Inc.) was inserted into the headspace of each vial to adsorb the volatile compounds at room temperature for 10 min. Desorption was at $230{ }^{\circ} \mathrm{C}$ for 10 min through splitless injection in a GC-MS instrument (6850GC with 5975MDS, Agilent Technologies, Santa Clara, CA) equipped with a DB-WAX column ( $60 \mathrm{~m} \times 0.25 \mathrm{~mm}$, film thickness $0.25 \mu \mathrm{m}$, Agilent Technologies). The conditions for GC-MS analyses were as follows: carrier gas, helium; flow rate, $1 \mathrm{~mL} \mathrm{~min}^{-1}$, column oven program $100^{\circ} \mathrm{C}$ initially, increasing by $4^{\circ} \mathrm{C}$ every min to $180^{\circ} \mathrm{C}$, and maintained at this temperature for $30 \mathrm{~min}$. Thereafter the temperature was increased by $5^{\circ} \mathrm{C}$ every min until it reached $240^{\circ} \mathrm{C}$, and this was maintained for 18 min. The ionization voltage for MS was $15 \mathrm{eV}$. Peaks were identified by comparing the retention times and mass fragmentation patterns of the samples with those from the literature $[9,10]$ and the National Institute of Standards and Technology database.

\section{Analyses of essential oil and hydrosol}

Agarwood oil (3 $\mu \mathrm{L})$ and hydrosol $(1 \mu \mathrm{L})$ samples were analyzed by GC (G-5000, Hitachi Ltd., Tokyo, Japan) equipped with a InertCap-WAX column $(60 \mathrm{~m} \times 0.25 \mathrm{~mm}$, film thickness $0.25 \mu \mathrm{m}$, GL Sciences). The split ratio was 99:1. The conditions for GC analysis were as follows: carrier gas, helium; flow rate, $1 \mathrm{~mL}$ min; injector temperature, $230^{\circ} \mathrm{C}$; detector; flame ionization detector (FID), $250^{\circ} \mathrm{C}$; column oven program, $100^{\circ} \mathrm{C}$ initially increased by $4^{\circ} \mathrm{C}$ every min until it reached $180^{\circ} \mathrm{C}$, maintained at this temperature for $30 \mathrm{~min}$, then increased by $5^{\circ} \mathrm{C}$ every min until it reached $240^{\circ} \mathrm{C}$, and maintained for $18 \mathrm{~min}$.

\section{Analyses and identification of compounds contained in hot water extract of agarwood}

The MeOH-soluble fraction of hot water extract of agarwood was analyzed by HPLC (pump, L-7100; column oven, L-7300; UV detector, L-7420, Hitachi Ltd.). Two conditions were set for the analysis: condition 1 covers a wide range of polarities and condition 2 is for the isolation of specific compounds.

Condition 1: YMC-Pack ODS/A column, $10 \mu \mathrm{m}, 4.6 \mathrm{~mm}$ I.D $\times 250 \mathrm{~mm}$; detection at $254 \mathrm{~nm}$; solvent, $\mathrm{MeOH}$-water; gradient from $37 \%$ (0 min) to $100 \%$ (30 min); flow rate, $1 \mathrm{~mL} \mathrm{~min}^{-1}$; and injection volume, $3 \mu \mathrm{L}$.

Condition 2: ${ }_{5} \mathrm{C}_{18} \mathrm{MS}-\mathrm{II}$ (COSMOSIL, Nacalai Tesque Inc., Kyoto, Japan) column, $4.6 \mathrm{~mm}$ I.D × 250 $\mathrm{mm}$; detection at $254 \mathrm{~nm}$; solvent, $\mathrm{MeOH}$-water; gradient from 20\% (0 min) to 30\% (60 min); flow rate, $1 \mathrm{~mL} \mathrm{~min}^{-1}$, and injection volume, $1 \mu \mathrm{L}$.

A Prominence series system (Shimadzu Corp., Kyoto, Japan) was used to isolate the target compound under the following conditions: Column, ${ }_{5} \mathrm{C}_{18}$ MS-II (COSMOSIL, Nacalai Tesque Inc.), $20 \mathrm{~mm}$ I.D $\times$ 
$250 \mathrm{~mm}$; detection at $254 \mathrm{~nm}$; solvent, $\mathrm{MeOH}$-water; gradient, from 20\% (0 min) to 30\% (60 min);

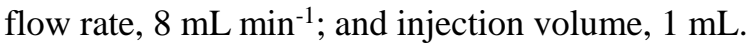

\section{Fractionation and identification of target compound}

The MeOH-soluble fraction from the hot water extraction was fractionated as follows: A solution of the hot water extraction was prepared by dissolving $50.6 \mathrm{mg}$ of freeze-dried hot water extract in $\mathrm{MeOH}$, filtered through filter paper, and evaporation to obtain $47.4 \mathrm{mg}$ of extract. The extract was again dissolved in $\mathrm{MeOH}$ at $15 \mathrm{mg} \mathrm{mL}^{-1}$, filtered (GL Chromatodisk 13P, $0.45 \mu \mathrm{m}$, GL Sciences), and separated by HPLC. Finally, $13.6 \mathrm{mg}$ of the target compound was obtained.

${ }^{1} \mathrm{H}$ - and ${ }^{13} \mathrm{C}-\mathrm{NMR}$ spectra were recorded on a $500 \mathrm{MHz}$ spectrometer (JNMECA500KP, (JEOL Ltd., Tokyo, Japan). The compounds were identified by comparing the data with those published in the literature [11].

\section{Results}

\section{Analyses of volatile compounds by heating agarwood}

Ground agarwood pieces were analyzed by HS-SPME-GC-MS. Sesquiterpenes and LACs such as benzylacetone and benzaldehyde were detected in the headspace vapor of the resinous part on heating. On the other hand, some compounds such as vanillin and furfural, which are thought to be decomposition products of wood, were detected in the headspace vapor of the non-resinous part on heating, and LACs like benzylacetone were absent (Table 1). Area\% of peaks in total ion chromatography of GC-MS were shown in Table 1 for reference.

\section{Analyses of essential oil and hydrosol}

The essential oil and hydrosol fractions were analyzed by GC and GC-MS. Sesquiterpenes were the main compounds detected in the essential oil. LACs were detected in the hydrosol in addition to sesquiterpenes (Table 2).

\section{Analyses of hot water extract of agarwood and identification of target compound}

Freeze-dried samples of hot water extracts of agarwood (4.0 mg) were analyzed by HS-SPME-GCMS. LACs such as benzylacetone and benzaldehyde were detected. These compounds were also found in the $\mathrm{MeOH}$-soluble fraction of hot water extract of agarwood. The MeOH-soluble fraction of hot water extract of agarwood was analyzed by HPLC. The HPLC chart showed a large peak that occupied approximately $60 \%$ of the total area of the chart (Fig. 1). NMR analysis showed that this compound was agarotetrol.

\section{Analyses of volatile compounds from heated agarotetrol}

Agarotetrol (6.84 mg) was heated to $190-200^{\circ} \mathrm{C}$ in a glass vial with a screw cap, and the volatile compounds in the headspace of the vial were adsorbed to an SPME fiber inserted through the septum of the cap. HS-SPME-GC-MS analysis showed the presence of benzylacetone, benzaldehyde, and benzenepropanoic acid methyl ester (Fig. 2). The contents in the vial were decreased to $6.70 \mathrm{mg}$ after heating.

\section{Discussion}

Agarotetrol was the main compound found in a hot water extract of agarwood and generated LACs, especially benzylacetone, by heating. The amounts of LACs in the oil increase if distillation is performed after soaking pieces of the wood in water for several days [3]. In fact, the process of oil distillation in agarwood-producing countries often includes soaking agarwood in water for several 
days before distillation. This process has been shown to contribute to increasing the amounts of LACs in essential oil as well as the production volume of the essential oil from limited agarwood resources. The structure of agarotetrol was first elucidated by Yoshii et al. in 1978 [12] and was shown to be widely present in agarwood regardless of the species or grade $[13,14]$. Some studies have investigated agarotetrol pyrolysis [5, 8, 15], but the relationship between agarotetrol in agarwood and the generation of benzylacetone in the volatile compounds of agarwood has not been clarified. The present experiment showed that LACs were detected when agarwood was heated to $190-200^{\circ} \mathrm{C}$ and were also detected in the volatiles of agarwood and in the $\mathrm{MeOH}$-soluble fraction of hot water extraction. According to these results, we suggest that agarotetrol contributes to the fragrance of agarwood.

Kishida et al. collected the essential oil of agarwood using hexane, and benzylacetone and benzaldehyde were detected in the oil fraction [3]. In this study, the essential oil and hydrosol of agarwood were collected without solvents and were analyzed separately. As a result, many kinds of polar LACs were detected in the hydrosol. The instrument for hydro-distillation was different from Clevenger type and the system was not a complete closed one. Thus, some LACs which were difficult to dissolve in water and easy to volatile, might vaporize into the air and weren't detected in hydrosol or essential oil. The hydrosol fraction of agarwood has barely been studied, but it turned out to be a good source of agarwood LACs because it contains some compounds that are difficult to collect by extraction methods using organic solvents.

Some of the LACs detected in the headspace vapor of resinous agarwood on heating were absent from the headspace vapor of non-resinous part. In a previous report, syringaresinol, a kind of lignin was detected in the non-resinous part, while chromones were detected in the resinous parts [16].

The detection of a series of chromone compounds during the cell cycle of cultured cells has been previously described: the amount of oxideagarochromones increases at an early stage and decreases as cell viability decreases. Thereafter, chromone derivatives such as agarotetrol and 6-methoxy-2-(2phenylethyl) chromone are formed. Conversely, sesquiterpenes can be produced by stimulating cells with methyl jasmonate, and are thought to be phytoalexins [17]. The biosynthetic pathway of chromones has not yet been clarified but they are not formed by methyl jasmonate.

Because of its high economic value and popularity around the world, agarwood sources are becoming depleted due to over-exploitation and the decreasing number of tropical rainforests. For these reasons, all species of the origin plants that create agarwood are listed in Appendix II of the 2005 Convention on International Trade in Endangered Species of Wild Fauna and Flora (CITES). Therefore, there is considerable interest in the production of agarwood on cultivated Aquilaria spp trees, and many procedures and reagents have been attempted. However, few have been successful, and the quality of agarwood is variable. Studies into the mechanisms of resin accumulation in agarwood are of interest in terms of scientific research on the one hand, and the agarwood market on the other. Some compounds derived from agarwood such as benzylacetone are potent sedatives when inhaled $[2,6]$. However, further investigation into the composition and synthetic mechanisms is needed to provide a scientific explanation for the effects of agarwood.

In this study, agarotetrol, a polar compound extracted from agarwood with water, was identified and shown to generate LACs on heating, especially benzylacetone. Agarotetrol and other chromone derivatives do not have a scent, although they are converted to LACs or other volatile compounds by heating to obtain the agarwood fragrance.

\section{References}

1. The Japanese standards for non-Pharmacopoeial crude drugs 2015, The Ministry of Health Labour and Welfare, Japan.

2. Takemoto H, Ito M, Shiraki T, Yagura T, Honda G (2008). Sedative effects of vapor inhalation of agarwood oil and spikenard extract and identification of their active compounds. J. Nat. Med. 62, 41-46

3. Kishida K, Ito M (2009). Components of Agarwood Oils and Their Effects on Spontaneous Motor Activity of Mice. Shoyakugaku Zasshi, 63 (2), 39-45

4. Neaf R (2011). The volatile and semi-volatile constituents of agarwood, the infected heartwood of Aquilaria species: A review. Flavor Fragr. J. 26, 73-89

5. Ishihara M, Tsuneya T (1993). Compounds of the Agarwood Smoke on heating. J. Essent. Oil Res., 5, 419-423 
6. Miyoshi T, Ito M, Kitayama T, Isomari S, Yamashita F (2013). Sedative Effects of Inhaled Benzylacetone and Structual Features Contributing to Its Activity. Biol. Pharm. Bull. 36 (9) 1474-1481

7. Takakuwa T, Shimizu M, Kubo K, Takeuchi F, Nishio S (1977). Koseikagakukenkyuhokoku, Showa 52 nendo, 92

8. Hashimoto K, Nakahara S, Inoue T, Shimada Y, Takahashi M (1985). A New Chromone from Agarwood and Pyrolysis Products of Chromone Derivatives. Chem. Pharm. Bull. 33 (11)5088-5091

9. C G Zambonin, Balest L, G E De Benedetto, Palmisano F (2005). Solid-phase microextraction-gas chromatography mass spectrometry and multivariate analysis for the characterization of roasted coffees. Talanta, 66, 261-265

10. Łucejko JJ, Modugno F, Ribechini, E, Del Río JC (2009). Characterisation of archaeological waterlogged wood by pyrolytic and mass spectrometric techniques. Analytica Chimica Acta 654, 26-34

11. Shimada Y, Konishi T, Kiyosawa S, Nishi M, Miyahara K, Kawasaki T (1986). Studies on the Agarwood (Jinko). IV. Structures of 2-(2-Phenylethyl)chromone Derivatives, Agarotetrol and Isoagarotetrol. Chem. Pharm. Bull. 34 (7)2766-2773

12. Yoshii E, Koizumi T, Oribe T (1978). THE STRUCTURE OF AGAROTETROL, A NOVEL HIGHLY OXYGENATED CHROMONE FROM AGARWOOD (JINKO). Tetrahedron Letters, 41, 3921-3924

13. Konishi T, Okutani Y, Iwagoe K, Kiyosawa S, Shimada, Y (1989). Studies of the Agarwood "Jinko" (IX)1) Quantitative Analysis of 2-(2-phenylethyl)chromone derivatives (Supplement). Shoyakugaku Zasshi, 43 (1), 1-6

14. Li J, Chen D, Jiang Y, Zhang Q, Zhang L, P F Tu (2013). Identification and quantification of 5,6,7,8-tetrahydro-2-(2phenylethyl)chromones in Chinese eaglewood by HPLC with diode array detection and MS. J. Sep. Sci. 36, 3733-3740

15. Uchino S, Takahashi S, Oguri N, Maoka T, Kozuka M, Shimada Y, Hashimoto K (1998). Compositional analysis of the fragrance gas from agarwood by using curie-point pyrolysis- GC/MS and comnustion-GC/MS. Chromatography, 19, No. 3

16. Yagura T, Shibayama N, Ito M, Kiuchi F, Honda G (2005). Three novel diepoxy tetrahydrochromones from agarwood artificially produced by intentional wounding. Tetrahedron Letters, 46, 4395-4398

17. Okudera Y, Ito M (2009). Production of agarwood fragrant constituents in Aquilaria calli and cell suspension cultures. Plant Biotechnology 26, 307-315 
Figure

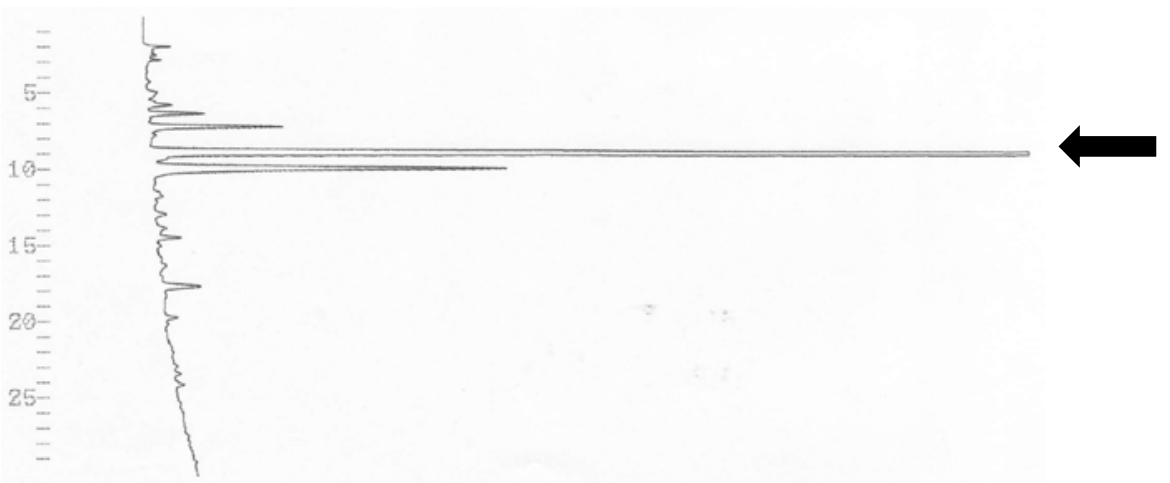

Fig. 1 HPLC chart of MeOH soluble fraction of hot water extract of agarwood in condition 1.

= a large peak that occupied approximately $60 \%$ of the total area of the chart<smiles>O=c1cc(CCc2ccccc2)oc2c1[C@@H](O)[C@H](O)[C@H](O)[C@H]2O</smiles>

agarotetrol

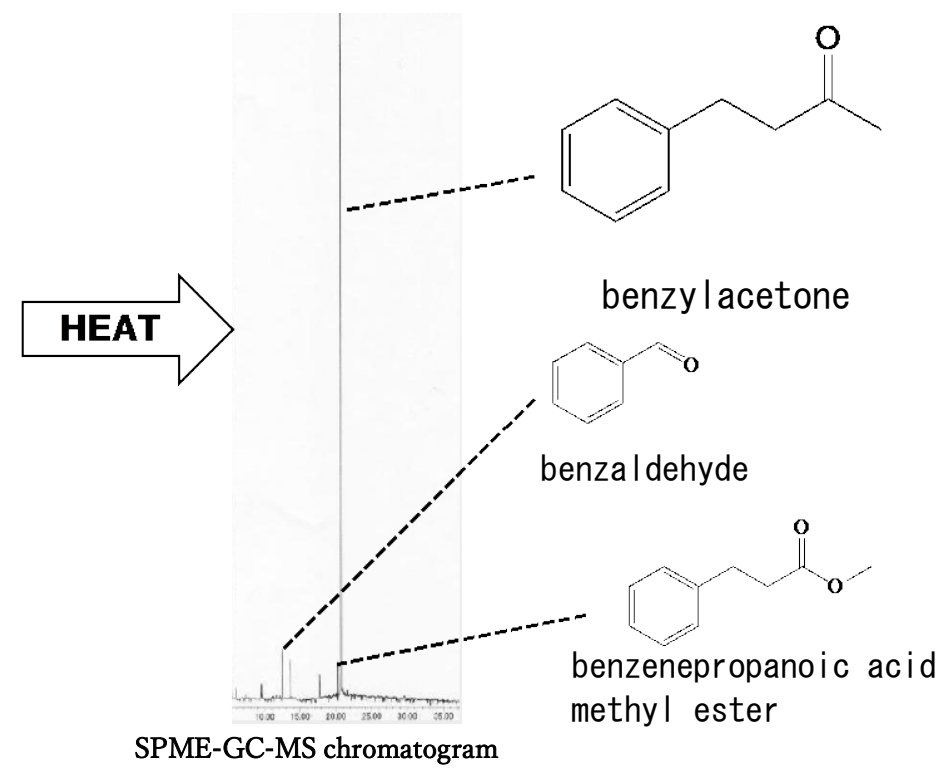

SPME-GC-MS chromatogram

Fig.2 Low molecular weight aromatic compounds generated from agarwood on heating. 
Table

Table 1 Compounds detected in the headspace vapor of resinous and non-resinous parts of agarwood.

\begin{tabular}{|c|c|c|c|}
\hline Compound & RI & Resinous part ${ }^{*}$ & Non-resinous part ${ }^{*}$ \\
\hline Furfural & 1420 & - & 5.66 \\
\hline Benzaldehyde & 1473 & 7.36 & - \\
\hline 4-Ethyltoluene & 1612 & 0.5 & - \\
\hline Acetophenone & 1635 & 0.86 & - \\
\hline 1-Furfurypyrrole & 1816 & - & 2.99 \\
\hline Benzylacetone & 1833 & 6.01 & - \\
\hline 2-Acetylpyrrole & 1887 & - & 0.61 \\
\hline Methyleugenol & 2005 & - & 0.92 \\
\hline 4-Methoxybenzaldehyde & 2015 & 0.69 & - \\
\hline (E)-Cinnamaldehyde & 2020 & 0.09 & 2.39 \\
\hline 8-epi- $\gamma$-Eudesmol & 2054 & 3.22 & - \\
\hline$\beta$-Eudesmol & 2213 & 0.16 & - \\
\hline Hydrocoumarin & 2231 & 0.14 & - \\
\hline Coumarin & 2421 & 0.11 & - \\
\hline Vanillin & 2548 & - & 0.56 \\
\hline
\end{tabular}

Shaded boxes indicate LACs that were detected in only the headspace vapor of the part on heating. $\mathrm{RI}=$ retention index on the DB-WAX column

"Data are shown as area\% of peaks in total ion chromatograms of GC-MS.

$-=$ absent 
Table 2 Compounds detected in the essential oil and hydrosol of agarwood

\begin{tabular}{|c|c|c|c|}
\hline \multirow[b]{2}{*}{ Compound } & \multirow[b]{2}{*}{ RI } & \multirow{2}{*}{$\begin{array}{l}\text { Hydrosol } \\
\text { Area (\%) }{ }^{* *}\end{array}$} & \multirow{2}{*}{$\begin{array}{l}\text { Essential oil } \\
\text { Area }(\%)^{* *}\end{array}$} \\
\hline & & & \\
\hline Furfural & 1418 & 0.04 & - \\
\hline Benzaldehyde & 1473 & 0.44 & - \\
\hline Acetophenone & 1636 & 0.24 & - \\
\hline Isoborneol & 1643 & 0.02 & - \\
\hline 2-Hydroxybenzaldehyde & 1650 & 0.01 & - \\
\hline endo-Borneol & 1659 & 0.37 & - \\
\hline Benzylacetate & 1671 & $\operatorname{tr}$ & - \\
\hline Benzylacetone & 1834 & 9.32 & - \\
\hline Benzylalcohole & 1839 & 0.08 & - \\
\hline 4-Phenyl-2-butanol & 2001 & $\operatorname{tr}$ & - \\
\hline 4-Methoxybenzaldehyde & 2016 & $\operatorname{tr}$ & - \\
\hline (E)-Cinnamaldehyde & 2022 & $\operatorname{tr}$ & - \\
\hline \multicolumn{4}{|l|}{ 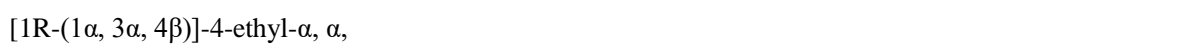 } \\
\hline 4-trimethyl-3-(1-methylethenyl)- & 2038 & 0.4 & 0.57 \\
\hline \multicolumn{4}{|l|}{ cyclohexanemethanol } \\
\hline 8-epi- $\gamma$-Eudesmol & 2055 & 1.79 & 10.27 \\
\hline (E)-Benzalacetone & 2056 & tr & - \\
\hline Eugenol & 2081 & 0.11 & - \\
\hline$\gamma$-Eudesmol & 2087 & 0.43 & 0.79 \\
\hline$\beta$-Eudesmol & 2215 & 3.39 & 1.81 \\
\hline
\end{tabular}

$\mathrm{RI}=$ retention index on the DB-WAX column

"* Quantified by their FID peak are

- = absent

$\operatorname{tr}=\operatorname{trace}$ 